\title{
A nova dinâmica das relações campo x cidade em Macaé: o exemplo da Comunidade Serra da Cruz
}

\author{
New dynamics of relations countryside x city in Macaé: \\ example of community Serra da Cruz
}

\author{
Nelson Jose Zampier Bonin \\ Universidade do Estado do Rio de Janeiro - UERJ - Rio de Janeiro - Rio de Janeiro - Brasil
}

\begin{abstract}
Resumo: Em face da constante complexidade das transformações socioespaciais, surgem interpretações no meio científico, que buscam analisar as reflexões entre cidade e campo. As atividades humanas estão modificando constantemente o espaço, e as mudanças ocorridas no campo despertam interesse de diversos pesquisadores, que podem seguir diferentes linhas de pesquisa. Este artigo trás uma contribuição ao debate sobre a questão cidade- campo e urbano-rural, contribuindo para aprofundar a reflexão sobre essa problemática. O exemplo da comunidade rural de Serra da Cruz, localizada no distrito de Glicério (Macaé-RJ), reflete a intensificação das implicações da atividade petrolífera no município, que amplia seu espaço urbano e torna mais dinâmico o rural. Apesar da pecuária de corte ser forte, o espaço agrícola municipal vem diminuindo, mas sobrevive e diversifica-se através da pluriatividade, do turismo, etc. O trabalho tenta exemplificar como as urbanidades entram na comunidade rural, modificando-a, mas não destruindo-a.
\end{abstract}

Palavras-chave: Campo-cidade. Rural-urbano. Pluriatividade.

\begin{abstract}
In the face of constant complexity of socio-spatial transformations, there are interpretations in the scientific community, which seek to analyze the reflections between town and country. Human activities are constantly changing space, and changes in the field arouse the interest of many researchers who can follow different lines of research. This article brings a contribution to the debate on the issue city countryside and urban-rural, contributing to further reflection on this issue. The example of the rural community of Serra da Cruz, located in Glicerio district (Macaé$\mathrm{RJ}$ ), reflecting the intensification of the implications of oil activity in the municipality, which extends its urban space and becomes more dynamic rural. Despite the beef cattle be strong, the municipal agricultural land is decreasing, but survives and diversifies through the pluriactivity, tourism, etc. The work attempts to illustrate how the urbanities enter the rural community, modifying it but not destroying it.
\end{abstract}

Keywords: Countryside-city. Rural-urban. Pluriactivity. 


\section{Introdução}

É notável que o campo, a partir da introdução de capital e maquinário modernos, sofreu transformações, não apenas na produtividade, mas nas relações de trabalho, na ampliação do êxodo rural, etc. O crescimento das áreas urbanas sobre as áreas rurais e modificação das suas relações, também modifica a definição do que é urbano e o que é rural. É objetivo do artigo discutir as correntes teóricas que tratam do tema dinâmica campo-cidade, inserindo o estudo sobre a Comunidade Serra da Cruz, que sofreu transformações, mas não deixou de ser uma comunidade rural.

Se pensarmos apenas em produção agrícola do Estado do Rio de Janeiro e Macaé, ela é relativamente baixa. Antes da implantação da Base de operações da Petrobrás em Macaé no final da década de 1970, o município sobrevivia de indústria sucroalcooleira, agropecuária e pesca. Com as atividades petrolíferas na Bacia de Campos, a que mais produz petróleo e gás no Brasil, Macaé recebeu migrantes de várias regiões do país e do mundo, em busca das oportunidades de emprego oferecidas pela instalação da Petrobrás e de várias empresas privadas. A atividade agrícola perdeu espaço para a indústria e serviços. Mas se pensarmos que o rural não é apenas agrícola, ele ganha importância, abrigando relações não agrícolas de trabalho, como o turismo em áreas rurais, etc.

No Brasil, o critério político administrativo define o que é urbano e rural. Considera-se urbana toda sede de município (cidade) e de distrito (vila). Segundo o IBGE, é considerada urbanizada toda área de cidade ou vila, legalmente definida como urbana e caracterizada por construções, arruamentos, áreas afetadas pelo desenvolvimento urbano, etc. De acordo com essa classificação, o rural corresponde àquilo que não é urbano, ou seja, por exclusão. $O$ rural e urbano são definidos pelo arbítrio dos poderes municipais e sua busca por interesses fiscais. Assim, segundo a Lei Municipal Complementar No 045/2004:
Das Zonas Urbana e Rural . Art. $3^{\circ}$ O território do município de Macaé,
em sentido amplo, fica subdividido em área
urbana e área rural.
$\& 1^{\circ}$ - Entende-se por área rural toda a parte
do território municipal não classificada como
área urbana.
$\& 2^{\circ}-$ consideram-se áreas urbanas as
parcelas do território municipal delimitadas
pelos perímetros urbanos das sedes distritais,
em conformidade ao constante nos cadastros
da Prefeitura.
$\& 4^{\circ}$ - As áreas urbanas compreendem dentro
de seus limites, às zonas urbanas e de
expansão urbana.

\& $1^{\circ}$ Entende-se por zonas urbanas aquelas que já tenham sofrido qualquer processo de parcelamento de solo para fins urbanos, ainda que não estejam totalmente ocupadas por edificações contínuas, e que possuam pelo menos 2 ( dois ) dos seguintes melhoramentos mantidos pelo poder público, conforme disposto em Legislação Federal:

a)meio - fio ou calçamento;

b)abastecimento de água;

c)sistema de esgoto sanitário;

d)rede de iluminação pública, com ou sem porteamento para distribuição domiciliar;

e)escola de ensino fundamental ou posto de saúde a uma distância de $3 \mathrm{Km}$ ( três quilômetros do local considerado ). (PREFEITURA DE MACAÉ, 2016)

A partir desse fragmento da legislação municipal de Macaé, parece ser difícil caracterizar o rural, pois na atualidade, as áreas rurais, em algum lugar, possuem alguns desses melhoramentos citados anteriormente.

\section{Metodologia}

Para a pesquisa, foi feita uma análise bibliográfica, com levantamento dos conceitos sobre rural, urbano, ruralidades e urbanidades, relação campo-cidade e da obtenção de dados através do site do IBGE, além de visita à Emater em Macaé. Foram realizadas duas visitas de campo, a primeira para observar os pontos de interesse da localidade Serra da Cruz e o trajeto, comparando com os dados já coletados em bibliografia; na segunda visita foi realizada entrevista (apenas conversa sem questionário) com um dos líderes da localidade, também um dos organizadores da Festa do Aipim. O entrevistado relatou a importância da festa, que é tradicional em Macaé, e sobre as dificuldades 
enfrentadas para sua realização, sob o ponto de vista de atender o público e sobre o patrocínio, que depende muito da verba da prefeitura. Antes da lei $n^{\circ}$ 9478, de 6/08/97 sobre a distribuição dos royalties, a Petrobrás patrocinava muitos eventos em Macaé, mas com a nova regulamentação o município passou a arrecadar muito dinheiro, e a Petrobrás passou a não atuar tanto, ou se afastou, investindo mais na área de seu interesse que é o distrito sede.

\section{Contribuição conceitual de alguns autores sobre a dinâmica campo-cidade, rural-urbano}

A dicotomia rural-urbano ou campo-cidade, coloca o conceito de rural numa posição contrária ao urbano, e este é visto como símbolo do desenvolvimento e dinamismo, apresentando atividades baseadas no setor industrial e de serviços, que comandam a economia e garantem renda superior à da zona rural (CÔRTES, 2008).

Segundo Graziano da Silva (1999), com a montagem do aparato industrial nas cidades, consumou-se a separação entre cidade e campo, e o discurso dicotômico de que a cidade era o símbolo do progresso e o campo a estagnação. Isso sob a ótica da produtividade. Essa abordagem dicotômica tem perdido força a partir das transformações no rural, sua integração com o urbano, além do rural não ser visto apenas como agrícola.

$\mathrm{Na}$ perspectiva dos trabalhos de pesquisa de Graziano da Silva (1999), Graziano; Del Grossi; Campanhola (2002), o espaço rural apresenta uma nova dinâmica socioeconômica, onde rural não está relacionado apenas às atividades agrícolas, pois o avanço tecnológico fechou campos de trabalho, mas fomentou abertura de novas oportunidades em atividades não agrícolas no campo, acelerando a reestruturação produtiva. Nessa visão, o processo de urbanização brasileira atinge o rural, transformando-o. Graziano avalia que esse "Novo Rural" surge na década de 1980 no Brasil, impulsionado principalmente pela formação dos Cais (complexos agroindustriais). No território rural, outras atividades passam a ser valorizadas: jardineiro, caseiro, outros serviços; além da diversificação da atividade agropecuária: fruticultura, horticultura, piscicultura, criações exóticas, etc.

Analisando as novas funções e ocupações no rural, ele é produzido ou reproduzido por pessoas que moraram no campo e foram para a cidade, e dela voltaram para o campo com novos pensamentos; os nativos do campo, hoje, tem mais contato com o mundo urbano e seu modo de vida. Esses velhos e novos personagens trilham um novo horizonte para as relações urbano-rurais. Esse "Novo Rural" não diz necessariamente que o velho rural acabou, apenas incorporou e transformou novas atividades.

Para Kayser (1989), em sua realidade francesa, está ocorrendo um renascimento rural, um repovoamento do rural, com novas atividades, o turismo, a descentralização industrial, local de segunda residência, etc. Apesar desse repovoamento, as atividades estritamente agrícolas diminuíram consideravelmente, aumentando a chamada pluriatividade. É importante ressaltar que muitos estudos como o de Kayser, de uma realidade europeia, influenciaram pesquisadores brasileiros a tratarem como nossa realidade, que é muito heterogênea.

Segundo Graziano Silva (1999), o "novo rural" é uma realidade no Brasil, envolvendo grandes transformações, desde a técnica de produção, tipo de mão de obra, até o que ele chama de "rurbanização", que pressupõem a incorporação das características urbanas ao campo; ou seja, é o que Graziano sempre defendeu, que está ocorrendo a urbanização do campo.

Alentejano (2000) questiona parcialmente o entendimento de Graziano Silva, na medida em que não afirma se há ou não uma nova realidade no campo brasileiro. Para ele, as transformações ocorridas a partir das décadas de 1970, com a modernização da produção agrícola, ainda não pressupõem um "novo rural", ou seja, para ele o rural ainda sobrevive com a concentração fundiária, com a pobreza; embora vivenciando a formação dos grandes complexos agroindustriais, expansão das monoculturas, etc. Alentejano mostra-se preocupado 
com a repercussão, até mesmo pela parte governamental, de que o rural é outro, o campo brasileiro todo se modernizou; e de fato isso ainda não aconteceu equitativamente. A preocupação também se relaciona à Política de Reforma Agrária, pois, se existe de fato um novo rural brasileiro, não há necessidade de políticas sociais vinculadas às mazelas do velho rural, que ainda coexistem no território nacional.

De acordo com Rua (2006, p.83), as relações de poder e o exercício da hegemonia têm se manifestado, em seus aspectos econômicos, políticos, culturais e simbólicos. Cidade e campo, urbano e rural, vem sendo percebidos como polaridades, nas quais a assimetria de poder e hegemonia, e as representações daí resultantes, tem mantido a cidade (e o urbano) como dominante na polarização que exerce. O campo (e o rural) vem sendo percebido, já há algum tempo, como mercadoria, capaz de gerar renda com a produção e a especulação das terras. Essa percepção tradicional ainda é muito comum, porém, na atualidade, são incorporados novos papeis, integrados a um movimento de ressignificação do rural, em que a natureza e seus atrativos do campo, tornam-se mercadorias valiosas. Então, além da terra e do trabalho sobre ela, novos atributos até imateriais, obriga-nos a repensar o modelo de produção baseado na terra-capital-trabalho. O capitalismo recria um rural, capaz de integrar-se, mesmo que desigualmente, a múltiplas escalas que marcam as interações espaciais do mundo atual (RUA, 2006, p.83).

Essa interação afeta, sobretudo, a (re)construção ou a própria manutenção da identidade social do agricultor, e seus reflexos territoriais. Esse processo, Rua (2006) chama de novas territorialidades, resultantes das interações urbano-rural e às identidades que a elas se integram.

$\mathrm{Na}$ política governamental brasileira, o rural tem sido percebido como agrícola (ligado à produção de alimentos), inclusive a agricultura de exportação é privilegiada, mostrando um olhar ainda tradicional para as funções do rural. Rua (2006) constata esse privilégio:
"O Estado, ao viabilizar os complexos agroindustriais e favorecer o empresariado rural em detrimento dos produtores familiares camponeses, tem mantido os velhos pactos entre os setores do bloco hegemônico, contando sempre com a resistência, algumas vezes manifestada com violência, desses camponeses que desenvolvem estratégias de sobrevivência particulares ou coletivas, quando integrados a movimentos sociais rurais (embora não exclusivamente com contingentes rurais) como o MST, o de maior expressão até o momento. (RUA, 2006, p.85)

Os produtores familiares tem se integrado ao mercado, e até aos complexos agroindustriais, por meio de modernização tecnológica, cooperativismo e associativismo, e a possibilidade de obter créditos, como os oferecidos pelo PRONAF.

A mudança organizacional no campo, fundamentada pelo modelo produtivo vigente, compõem transformações mais amplas na sociedade brasileira. De acordo com Rua (2006), essas novas representações orquestradas pelo capitalismo, não sendo definidas como "um novo rural". Na verdade vai além daquela visão produtivista do espaço rural e agrícola, diversificando as relações entre rural e urbano e entre o campo e a cidade. Nessa visão, o rural distancia-se do apenas agrícola; a distinção entre cidade e urbano fica mais complexa e o rural e o urbano fundem-se, mas sem se tornarem a mesma coisa, já que preservam suas especificidades.

Para evidenciar o processo citado acima, podemos citar o processo de industrialização, no qual, muitas vezes a indústria "ruraliza-se", pois os serviços se estendem ao campo, reforçando aquilo que João Rua chama de "urbanidades no rural", aceleradas pela industrialização do campo e da própria agricultura. Nessa perspectiva o capitalismo recria o campo constantemente, impondo a ele o que produzir, quanto produzir, o que utilizar para produzir (técnicas, equipamentos, insumos). O tradicional corte rural/urbano desaparece; a pluriatividade, que mescla atividades não agrícolas (a maioria de caráter urbano) e agrícolas no espaço rural; o aumento da produtividade e a consequente diminuição do tempo necessário para o trabalho agrícola a partir da 
mecanização, liberando o agricultor a dedicar-se parcialmente à agricultura, podendo dedicar-se à outros tipos de trabalho e incorporar outras fontes de renda ao orçamento familiar; surgem novas atividades no campo; localização de fábricas no campo e a difusão do trabalho industrial no campo. Fora da unidade produtiva do campo, os membros da família dedicam-se cada vez mais à prestação de serviços (tratorista, frentista, piloto agrícola, comerciário, etc). Essa caracterização da chamada pluriatividade marca uma nova relação com a terra, permitindo ao agricultor manter sua família.

Para alguns autores que pregam o fim do rural, enxergam a pluriatividade como o início da decadência. No entanto, a diversificação do trabalho e renda, é um movimento de renovação do campo, que se integra a novas lógicas.

De acordo com Schneider (2003), o debate sobre a pluriatividade têm início nos países desenvolvidos, especialmente na Europa, a partir da década de 1970, embora essa forma de produção tenha início bem antes disso. Esse mesmo autor define o fenômeno da pluriatividade:

[...] podemos definir a pluriatividade como um fenômeno através do qual membros das famílias de agricultores que habitam no meio rural optam pelo exercício de diferentes atividades, ou mais rigorosamente optam pelo exercício de atividades não agrícolas, mantendo a moradia no campo e uma ligação inclusive produtiva, com a agricultura e a vida no espaço rural. Nesse sentido, ainda que se possa afirmar que a pluriatividade é decorrente de fatores que lhe são exógenos como o mercado de trabalho não agrícola, ela é uma prática que depende das decisões dos indivíduos e das famílias (SCHNEIDER, 2003, p.91-92).

Schneider procura não mitificar a pluriatividade enquanto solução para todos os problemas enfrentados no campo, mas como possibilidade alternativa para os agricultores e suas famílias obterem novas formas de emprego, aumentar a renda, garantindo assim, maior estabilidade no meio rural.

Moreira (2003) não discorda de Schneider, mas vê uma transformação maior através das pluriatividades, principalmente no aspecto de valorização da natureza, por isso, descreve uma multifuncionalidade do território, com base na pluriatividade:

\begin{abstract}
Esse (novo mundo rural) passa a ser compreendido não mais como espaço exclusivo das atividades, mas como lugar de uma sociabilidade mais complexa que aciona novas redes sociais regionais, estaduais, nacionais e mesmo transnacionais. Redes sociais as mais variadas que no processo de revalorização do mundo rural, envolvem a reconversão produtiva (diversificação da produção), a reconversão tecnológica (tecnologias alternativas de cunho agroecológico e natural), a democratização da organização produtiva e agrária (reforma agrária e fortalecimento da agricultura familiar), bem como o fortalecimento do turismo em áreas rurais (ecológico e cultural) (MOREIRA, 2003, p.132).
\end{abstract}

Essa diversificação das atividades, a valorização da paisagem natural e cultural local, dinamizam a produção de agricultores familiares e o próprio comércio local, consolidando atividades rurais e urbanas em áreas interioranas.

Santos (1999, p.82) define o espaço como um híbrido, e sua existência geográfica (dos objetos) é dada pelas relações sociais a que o objeto se subordina, e que determinam as relações sociais técnicas ou de vizinhança mantidas com outros objetos.

Haesbaert (2005, p.5) sintetiza que hibridização implicaria, a princípio, também, em territórios múltiplos, territórios híbridos ou que as pessoas e grupos sociais desenvolvam concomitantemente, vínculos identitários com mais de um território ou com territórios de características muito mais híbridas, multiterritorializando-se.

Segundo Rua (2006, p.89), a produção de um rural híbrido transcende as condições materiais e os processos que Ihes dão origem. Alguns autores veem a urbanização como destino final do espaço; outros veem o rural como resistência ao poder do urbano, e poucos tem uma visão mais integradora das territorialidades em que o urbano e o rural se mesclam definindo cada localidade.

Rua sugere duas vertentes analíticas que trabalham a temática estudada: a primeira com a ideia de urbanização do rural, e a segunda com a 
ideia de urbanização no rural. A primeira vertente, com a ideia de urbanização do rural, caminha para o desaparecimento do rural ou a incorporação do mesmo pelo urbano, isso numa análise simplificada. Nessa visão, a "urbanização do rural pode ser relacionada à ideia de continuum rural, em que haveria graus distintos de urbanização do rural, como enfatizado nas obras de lanni (1996) e Graziano da Silva (1999), além de Santos (1999).

A partir da leitura de Santos sobre as interações local/global, notamos que há necessidade de uma abordagem multiescalar, defendida na segunda vertente, que Rua (2006) denomina "urbanização no rural", que mantém suas especificidades no rural, mesmo sob a força avassaladora do urbano. Nessa segunda vertente, segundo Rua (2006), apesar da diversidade entre os autores, defende a ênfase no rural, na ideia de "novas ruralidades". Entre os autores está o próprio Rua (2005), Maria Jose Carneiro (1998), Roberto José Moreira (2003), José Eli da Veiga (2004), Ricardo Abramovay (2000) e Sérgio Schneider (2003). Até a própria formação desses autores acaba tendenciando a organização das ideias. Alguns autores como Abramovay (2000) e Veiga (2004), tem uma visão mais economicista e normativa; os outros autores levam em consideração, num mesmo espaço, as particularidades da cultura urbana, o que colabora para a ideia de urbanidades no rural. É importante ressaltar que, tanto os autores da primeira vertente, quanto os da segunda vertente tem a sua contribuição para os estudos das transformações no rural.

Carneiro (1998, p.59) afirma que não podemos entender a ruralidade apenas pela mão única da penetração do urbano-industrial no campo, mas como uma mão dupla, onde a sociedade urbano-industrial consome bens simbólicos e materiais, como os produtos naturais e o aproveitamento das belezas naturais do mundo rural. A autora entende, então, a ruralidade como um processo dinâmico, em constante reestruturação da cultura local, incorporando novos valores, hábitos e técnicas, decorrentes de novas relações cidade / campo. E importante entender que a ruralidade não é uma oposição à urbanidade, mas que a revalorização da natureza cria uma urbanidade contemporânea que valoriza a vida no campo. De acordo com Candioto e Corrêa (2008), além da população rural possuir suas ruralidades (que vem se modificando diante da relação com o urbano e a evolução da técnica), a população urbana também acaba apresentando ruralidades, ligadas ao interesse pelo rural. É assim que Moreira (2002, p.21) identifica a existência dessa troca entre urbano-rural e viceversa. Locatel (2004, p.9), também concorda que urbano e rural sejam vistos de forma complementar, negando a oposição entre os dois.

Carneiro (2001, p.13) explica que o fato de alguns hábitos serem modificados pela introdução de infraestrutura ou o contato direto com a população urbana, é insuficiente para acabar com a cultura rural. Segundo essa autora, a troca de experiência pode enriquecer ambos os lados.

A primeira vertente, segundo dados estatísticos, parece mais conveniente, considerando que o Estado do Rio de Janeiro possui taxa de urbanização de mais de 96\%, sendo o Estado mais urbanizado do Brasil, e Macaé com mais de 98,1\% de urbanização. Se considerar-mos apenas a estatística, o rural está acabando. Na segunda vertente, que leva em consideração escalas diferentes para determinados espaços, também respeita os diferentes atores sociais e suas ações sobre o território, marcando o surgimento de espaços híbridos transformados pelas relações entre o urbano e o rural, onde pode surgir algo novo e inovador.

De acordo com Rua (2006, p.95):

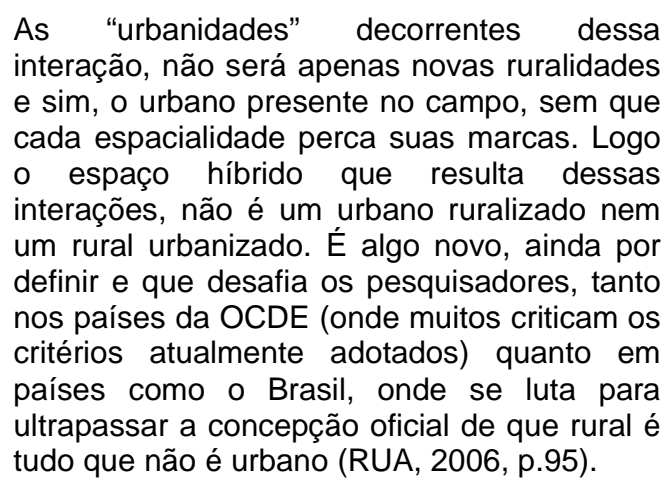

Percebe-se que a ressignificação do rural não é fruto apenas de criações urbanas, mas também por 
parte dos habitantes das áreas rurais, criando um caráter híbrido ao território e às identidades criadas com componentes "rurais" e "urbanos". Isso fica bem nítido na região serrana de Macaé, principalmente a partir da urbanização dos distritos e do asfaltamento da RJ 168, que liga a Sede Municipal à região serrana, com o aumento no fluxo de carros e pessoas, que influenciam o rural, e este adota estratégias para aproveitar economicamente, mas preservando a identidade local.

Rua (2002) diferencia a urbanização física da urbanização ideológica no rural, explicando que a urbanização ideológica, cultural, extensiva, difusa (apontada por ele como urbanidades), ocorre em escalas diferentes, de global a local, que impacta através da mudança de comportamentos, influenciados fortemente pela TV e outras mídias. Já a urbanização física, seria o crescimento material, formal de partes do espaço rural por construções. Assim, Rua (2005) e Candioto e Corrêa (2008), concordam que a urbanização ideológica sobressai sobre a física.

Candioto e Corrêa (2008) apontam as ruralidades como objetos e ações características do rural, e fazem parte da identidade da população rural, enquanto as urbanidades corresponderiam a objetos e práticas de caráter urbano, mas ambas estão interligadas, assim como o urbano está no rural, o rural está no urbano (músicas, festas, hortas, culinária, criação de animais).

Rua (2002, 2005) entende que o conceito de ruralidade é insuficiente para apreender a entrada de valores, ações e objetos de caráter urbano no rural, e ao questionar a existência de um amplo processo de urbanização física no campo, desenvolve sua reflexão sobre o conceito de urbanidades, lembrando que ele concorda que tanto a urbanização física, quanto a ideológica no campo levam ao estabelecimento de urbanidades no rural. Rua (2005) privilegia a dimensão identitária das ruralidades e urbanidades, entendendo-as como territorialidades.

De acordo com Candioto e Corrêa (2008), os objetos técnicos influenciam a percepção de indivíduos e grupos sociais sobre o que é rural e urbano. Um objeto técnico como a TV a cabo, internet, parabólica; pode conduzir a novas territorialidades, tanto na população urbana, mas principalmente nas rurais. Esses objetos técnicos podem mudar o comportamento e o padrão de consumo da população, criando novas territorialidades. Por isso que Rua (2005) usa muito o conceito de Haesbaert (2004) sobre multiterritorialidade.

\section{O Exemplo da Comunidade Rural de Serra da Cruz}

O Município de Macaé situa-se na Mesorregião Norte Fluminense, a nordeste do Estado do Rio de Janeiro, e está dividido em seis distritos (Fig.1):

Figura 1 - Macaé e seus Distritos

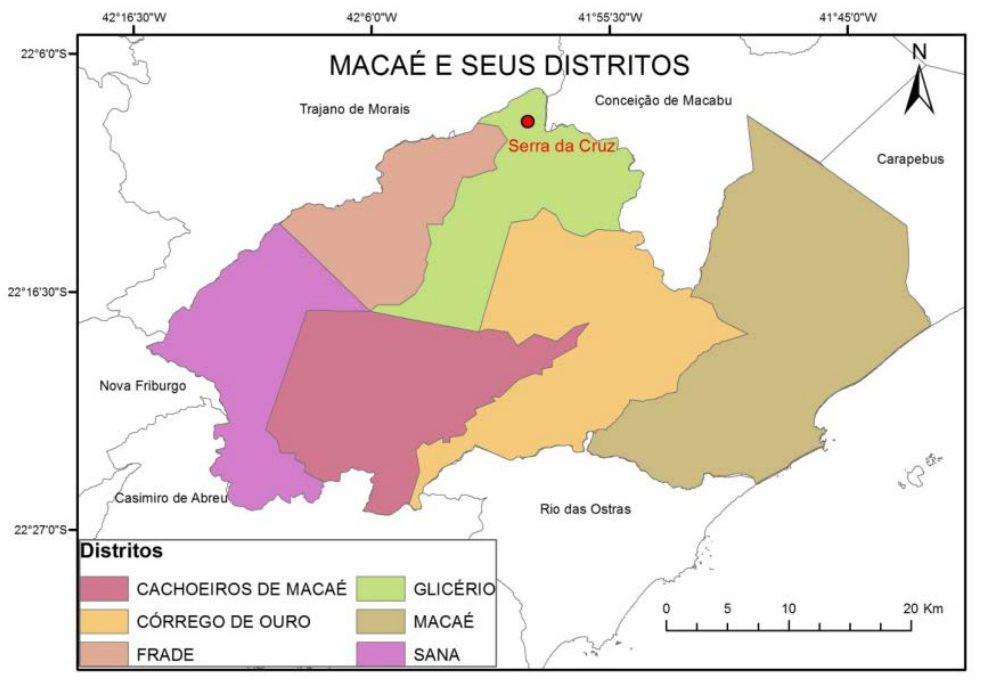

Fonte: Elaboração própria a partir da base de dados do IBGE.

Segundo o censo IBGE (2010), Macaé contava com 206.748 habitantes e, estimativa 2016 (IBGE) para 239.471 habitantes. Sua área é de 1.216,846 $\mathrm{Km}^{2}$ (IBGE), abrigando paisagens heterogêneas, com praias oceânicas, planícies e serras, áreas de Mata Atlântica, etc. A sede está localizada na porção sudeste do município, entre as coordenadas $22^{\circ} 22^{\prime} 15^{\prime \prime}$ de latitude sul e $41^{\circ} 47^{\prime} 13^{\prime \prime}$ de longitude oeste (IBGE).

A atividade petrolífera atrai muitas empresas e migrantes, aumentando a urbanização e a circulação 
dentro do território. Com o crescimento urbano de Macaé, novas vias de trânsito são construídas em território rural, que tem suas margens ocupadas por casas e empresas. Esse crescimento da cidade transforma constantemente o território, tanto o urbano quanto o rural, modificando também suas relações.

Para realçar melhor o exemplo de urbanidades no rural macaense, investigamos o exemplo da festa do aipim na Comunidade Serra da Cruz, que é uma localidade pertencente ao distrito de Glicério. Para chegar a esse local, quem vem de Macaé (sede), deve seguir a Rodovia RJ-168 até Trapiche, uma localidade urbana do distrito de Glicério, depois continuar por estrada não pavimentada até a localidade rural de Serra da Cruz. A distância do centro de Macaé até Serra da cruz é de $55 \mathrm{Km}$, ou seja, de carro faz o trajeto em aproximadamente 45 minutos. Ônibus coletivo percorre todo o trajeto, demorando um pouco mais.

Antes da chegada da Petrobrás em Macaé, os distritos da Serra Macaense eram bastante isolados, pouco povoados, as estradas não eram pavimentadas, e a população vivia quase exclusivamente da agricultura e pecuária. A partir da década de 1970, com a instalação da base de operações em Macaé, muitas empresas instalaram-se no distrito Sede, e a população, que na década de 1970 era de 65.453 habitantes, passou para 131.550 habitantes em 2000, 206.748 em 2010, e a estimativa da população em 2016 é de 239.471 habitantes (IBGE). A pressão populacional e a especulação imobiliária próximo ao litoral, devido a instalação das empresas, fez com que muitas pessoas procurassem a região serrana do município, em busca de moradia fixa, moradia de segunda residência, ou refúgio nos finais de semana. Houve o asfaltamento das estradas, aumentando o fluxo Macaé-Serra, e os distritos serranos cresceram. Foi criado um hospital na localidade do Trapiche, melhorando a infraestrutura da Serra. A comunidade de Serra da Cruz, que possuía apenas sítios, com poucas pessoas, que viviam exclusivamente da agricultura, passou a receber turistas em busca das belas paisagens e aventuras, além do que muitas pessoas passaram a comprar valorizadas chácaras no local.

A produção de Aipim é comum na localidade, que já constava com um moinho de farinha, mas em 2012 a Prefeitura de Macaé reequipou e reativou a fábrica de farinha de Serra da Cruz (Fig.2), que é uma das áreas que mais produz aipim no município.

\section{Figura 2 - Fábrica de Farinha em Serra da Cruz}

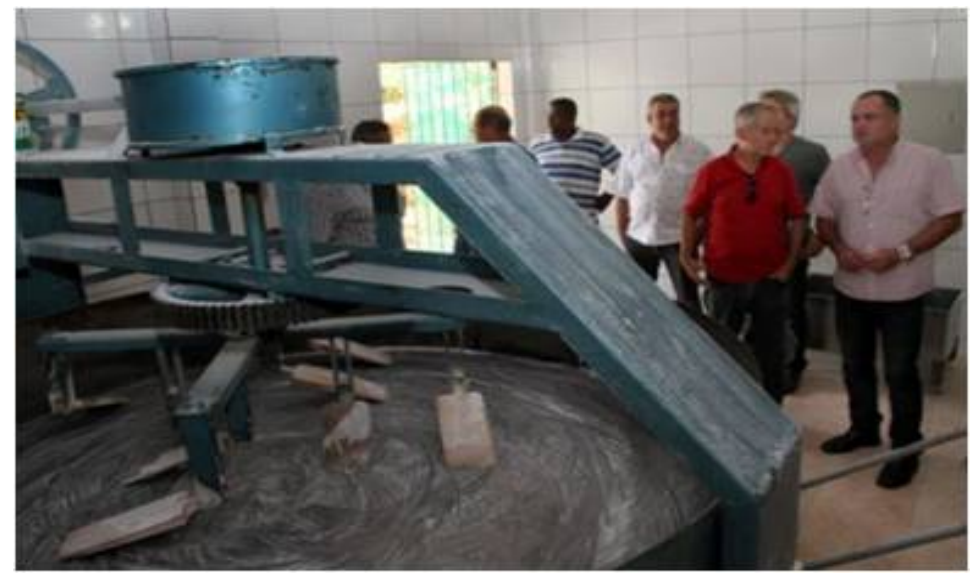

Fonte: Prefeitura de Macaé, 2015

Os produtores de Serra da Cruz consomem parte da produção, vendem e, na fábrica de farinha é processado o restante da produção que está "passada", ou seja, serve para fazer a farinha. Então, a fábrica, apesar de pagar um preço menor, ajuda o produtor manter a cultura renovada e a tradição.

O plantio da mandioca não necessita de áreas extensas, conseguindo boa produção por hectare. Através da tabela 1 observamos a produção desta cultivar ao longo dos anos.

\section{Tab.1 - PRODUÇÃO DE MANDIOCA NO MUNICÍPIO DE MACAÉ - RJ, ANOS SELECIONADOS}

\begin{tabular}{ccc}
\hline ANO & $\begin{array}{c}\text { Área plantada } \\
\text { (Hectares) }\end{array}$ & $\begin{array}{c}\text { Quantidade } \\
\text { produzida } \\
\text { (Toneladas) }\end{array}$ \\
\hline $\mathbf{2 0 0 0}$ & 180 & 2.340 \\
$\mathbf{2 0 0 3}$ & 150 & 1.950 \\
$\mathbf{2 0 0 6}$ & 100 & 910 \\
$\mathbf{2 0 0 9}$ & 100 & 1.000 \\
$\mathbf{2 0 1 1}$ & 100 & 1.000 \\
$\mathbf{2 0 1 3}$ & 150 & 1.500 \\
$\mathbf{2 0 1 4}$ & 155 & 1.550 \\
\hline
\end{tabular}

Fonte: IBGE, Pesquisa Agrícola Municipal (2000 a 2014) 
Percebemos que a área plantada e a quantidade produzida de mandioca ${ }^{1}$ já foi maior em Macaé. Mesmo assim essa cultura é muito importante para a comunidade local, não só de Serra da Cruz, mas dos outros distritos.

O trabalho reflete sobre as transformações socioespaciais, econômicas e culturais na comunidade. A pesquisa ajuda a compreender como a cultura de massa impõe o ritmo de consumo atual, com isso, interferindo na agricultura camponesa.

O estudo sobre as urbanidades no rural trás um debate assíduo para a geografia. Rua (2006) explica o termo urbanidades no rural, como todas as manifestações do urbano em áreas rurais, mas sem que essa presença ou influência leve a eliminação das marcas próprias de cada espacialidade.

A comunidade de Serra da Cruz promove o festival do aipim no mês de julho, aproximadamente há 17 anos, onde moradores e comerciantes comemoram a colheita do aipim. A festa tem o apoio da secretaria de agroeconomia, EMATER-RJ e no passado, até da Petrobrás em determinados anos.

Estão presentes na programação a missa, a tradicional quadrilha, bingo, leilão de prendas e a coroação da rainha do aipim, além do forró. O costume da missa em ação de graças pelos frutos da terra, herança dos antigos Judeus, foi mantido pela igreja cristã primitiva e persiste até o presente momento.

De acordo com entrevista (diálogo) feita com um morador e colaborador na organização da festa, nas barracas são ofertados vários pratos a base de aipim (bolo, tapioca, aipim frito, cozido, outros). Podem montar barracas aquelas pessoas que produzem na localidade ou que não produzem, mas foram convidadas pela direção da festa, para oferecerem mais serviços e produtos no atendimento

\footnotetext{
${ }^{1}$ A mandioca é uma espécie domesticada nas terras da América, pelos povos pré-colombianos, principalmente os da Amazônia. Existe a mandioca brava e a mandioca mansa, sendo o Brasil um dos maiores produtores do mundo. No Sul é chamada de aipim, no Nordeste, de macaxeira ou simplesmente mandioca, depende da região. A mandioca mansa é a mais utilizada na área doméstica; já a brava possui mais toxinas, necessitando passar por processo de desintoxicação, o que a torna pouco utilizada (VALLE, 2007, p.1-11).
}

ao público, que se torna mais variado e consumista. São feitas algumas premiações aos vencedores, nas categorias de melhor prato, prato surpresa, padrão comercial e produtividade. Os prêmios são em dinheiro e insumos agrícolas. Nos dias de festa a EMATER promove palestras e pequenos cursos sobre cultivos.

Essa manifestação enraizou na localidade, sendo a festa mais cobiçada no distrito, que já contagiou todo o município de Macaé e redondeza. Essa expansão abre espaço para a "invasão" de novas urbanidades no rural. Muitas pessoas da zona urbana de Macaé e região gostam da paisagem serrana com sua tranquilidade e, passam a comprar casas, terrenos, alugar; trazendo consigo os seus costumes urbanos e misturando com a população local. Os próprios pratos, antes feitos basicamente com aipim, hoje tem o aipim como complemento, mesmo que ainda importante; mas no caso do bolinho de aipim, são vários os recheios não típicos daquela zona rural.

A tradicional quadrilha, que possuía o estilo "jeca tatu", hoje é mais country, com vestimentas e músicas diferentes, etc.

Outra forma de urbanidade no rural, impulsionada pela sociedade de consumo é a inserção de apresentação de equipes de MotoCross nos dias da festa, que não tem haver com o cotidiano da maioria das pessoas que moram naquele lugar, mas os visitantes consomem esse nicho de aventura, abrindo as portas para outra fonte de renda para muitas famílias.

É importante refletir a partir de uma visão não dicotômica entre cidade e campo ou entre urbano e rural. Em seu processo de formação, cidade e campo são diferentes; porém não devem ser vistos como espaços que se opõem. Na relação cidade-campo deve-se considerar a distinção, a complementação, para compreender sua existência social. $\mathrm{Na}$ atualidade, essas relações passam por transformações que necessitam de um novo entendimento, cuja compreensão necessita de uma visão da totalidade, como na visão de Lefebvre (1991), que sinaliza para uma urbanização mundial 
acelerada da sociedade, mas não deixando de considerar a existência e o papel de espaços rurais.

A expansão das atividades econômicas em Macaé, principalmente com o aumento da exploração de petróleo pós década de 1990 e especulação de imóveis na área urbana central, muitas pessoas que chegaram a Macaé, não conseguiram se manter no litoral e foram morar nos distritos da Serra; outras pessoas procuraram a beleza e tranquilidade da Serra e seus distritos, tanto na área urbana, quanto na área rural, como é o caso da Comunidade Serra da Cruz, que não possui asfalto, mas é atendida por linha de ônibus. Nessa comunidade, habitam petroleiros, médicos aposentados, professores, pessoas que se fixam ou possuem segunda residência.

Serra da Cruz é uma localidade rural, no entanto, muitas pessoas que residem ali, não trabalham na agropecuária, mas gostaram do lugar, em contato com a natureza (Fig.3), longe do tumulto da cidade. Porém, como o fluxo de pessoas é intenso nos finais de semana e na época de festas populares, o contato do urbano é tão intenso, que parece misto de urbano e rural, o que em nosso entendimento é importante para o trabalho, pois ali, com os contrastes culturais, surgem transformações e novas territorialidades, sem perder as características da população, mas acrescentando novos conhecimentos. Na figura 4 podemos observar uma parte da localidade, com casas não muito próximas, nem muito distantes das outras.

Figura 3 - Cachoeira da Arataca, na fazenda São Miguel em Serra da Cruz

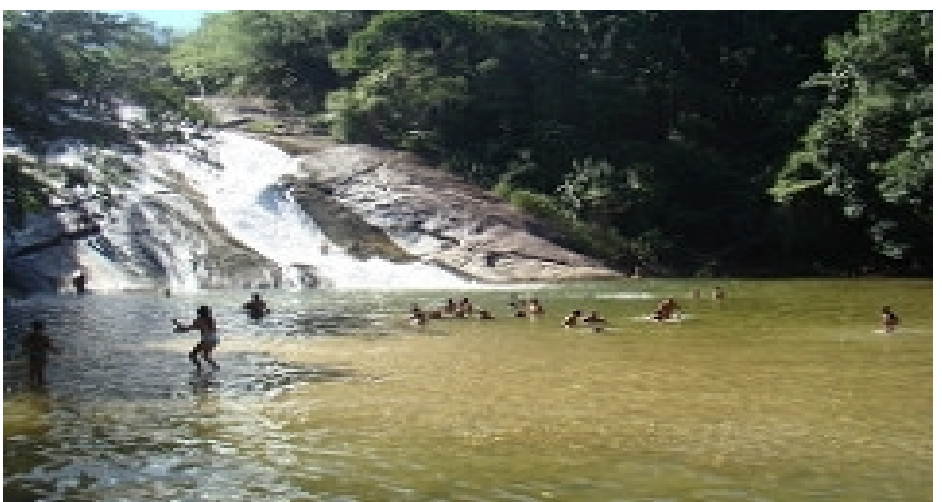

Fonte: Acervo da Prefeitura de Macaé ( 2016 )
Figura 4 - Imagem mostrando paisagem de parte da comunidade Serra da Cruz

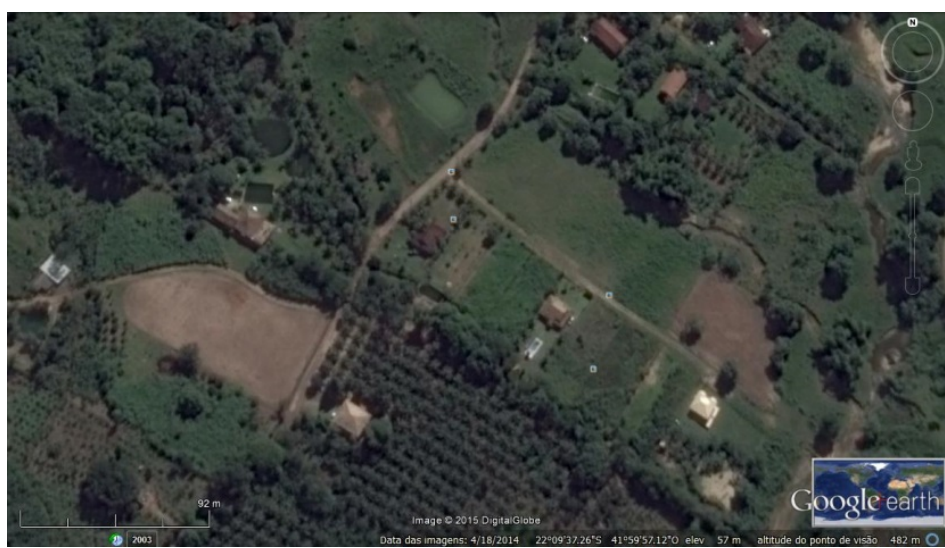

Fonte: Google Earth, 2016.

Entre Trapiche e Serra da Cruz ainda está localizado o Hotel Fazenda Trapiche (Fig.5), inaugurado em 2005 e reinaugurado em 2013, cujo lema do lugar é ser um hotel ecológico, que traz em sua essência o contato com a natureza, respeitandoa, distanciando os hóspedes dos tumultuados centros urbanos. O hotel atrai visitantes para a localidade, trazendo seus costumes, sendo influenciados pelos costumes locais, e conjuntamente criando novas ruralidades e urbanidades. Nesse hotel, que é um elemento urbano no rural, a pluriatividade é comum, através dos moradores que trabalham como jardineiros, camareiras, cozinheiras, motoristas e guias. Essas novas atividades, principalmente nesse exemplo, ajudam o trabalhador rural a conseguir outra fonte de renda sem ter que sair para trabalhar em local muito distante da sua moradia.

Figura 5 - Hotel Fazenda Trapiche

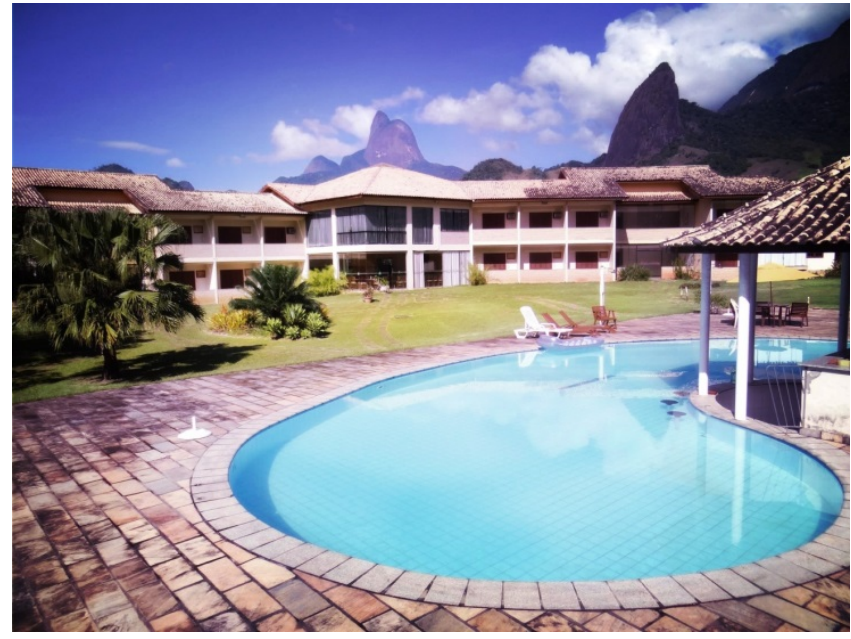

Fonte: hotelfazendatrapiche.eco.br (2016) 
O Trapiche é um hotel ecológico, composto de 42 suítes com vista para a natureza, equipadas com TV a cabo, frigobar, ar condicionado e cama king size, sendo que nas suítes másteres estão ainda equipadas com hidromassagem. O visitante pode aproveitar as belezas do lugar e as identidades da população local, promovendo relações entre o urbano e o rural. O estudo sobre a comunidade Serra da Cruz e sua dinâmica campo-cidade foi importante para relacionar estudos teóricos já realizados em outras comunidades, por autores consagrados no assunto dinâmica campo-cidade, como Rua(2002,2005,2006), Abramovay (2000), Alentejano (2000), Moreira (2002,2003), Graziano da Silva (1999,2002), Carneiro (1998), Veiga (2004), Schneider (2003) e outros autores, com o estudo empírico realizado na Serra da Cruz.

\section{Considerações finais}

A problemática da questão campo-cidade, urbano-rural, é muito mais ampla que a trazida neste texto, tampouco foi a intenção de esgotar o debate. Contudo, contribuímos em algumas considerações sobre essa nova dinâmica exposta no decorrer do texto. É importante ressaltar que Macaé cresceu rapidamente a partir da chegada da Petrobrás na década de 1970, e que o distrito sede (Macaé) abrigou a quase totalidade das empresas, com isso sua urbanização foi acelerada e transformadora. O município sobrevive especialmente da movimentação de empresas vinculadas ao ramo do petróleo e dos royalties e participações, com isso, este artigo também contribui na informação de que ainda existe o rural e o agrícola em Macaé. O exemplo da Comunidade Serra da Cruz enfatiza um desenvolvimento rural diferente do tradicional, que é aquele a partir da tecnologia, da mecanização; mas de uma transformação e adaptação.

A dicotomia campo-cidade e rural-urbano entra no debate seguindo diferentes análises de autores renomados nesta temática, o que contribui em nossa proposta de entender as novas relações a partir de urbanidades e ruralidades nos espaços. O campo não é visto apenas como agrícola, podendo relacionar com a cidade a partir de outras formas, além da produção de produtos, mas como válvula de escape para a conturbada vida nas cidades, através do turismo em áreas rurais, casas de veraneio, etc. Isso contribui para a manutenção da identidade cultural das localidades e sua população, como vem acontecendo na comunidade Serra da Cruz em Macaé, além de diversificar com as novas urbanidades no rural e vice versa.

\section{Referências}

ABRAMOVAY, Ricardo. Funções e medidas da ruralidade no desenvolvimento contemporâneo. Rio de Janeiro: IPEA, jan., 2000, 31 p.

ALENTEJANO, Paulo Roberto. O que há de novo no rural brasileiro? Revista Terra Livre, São Paulo, n.15, p.87 - 112, 2000.

CANDIOTTO, Luciano Zanetti Pessôa; CORRÊA, Walquíria Kruger. Ruralidades, urbanidades e a tecnicização do rural no contexto do debate cidade-campo. Campo-território: revista de geografia agrária, Uberlândia, v. 3, n. 5, p. 214242, fev. 2008.

CARNEIRO, Maria. Do rural e do urbano: uma nova terminologia para uma velha dicotomia ou a reemergência da ruralidade. Campinas, NEA Instituto de Economia - UNICAMP, 2001.

CARNEIRO, Maria. Ruralidade: novas identidades em construção. In: Revista Estudos, Sociedade e Agricultura. Rio de Janeiro: CPDA/UFRRJ: 1998.

CORTÊS, Cesar Pessôa. Análise da Agricultura Familiar no Município de Sumidouro/RJ. Dissertação de Mestrado. UERJ, 2008, 154 p.

IBGE - INSTITUTO BRASILEIRO DE GEOGRAFIA E ESTATISTICA. SIDRA - Sistema IBGE de Recuperação Automática. Disponível em: www.ibge.gob.br Acesso em: fev de 2014.

GRAZIANO da SILVA, J. O Novo Rural Brasileiro. Campinas: UNICAMP, 1999.

GRAZIANO da SILVA, J.; DELGROSSI, M.E.; CAMPANHOLA,C. "O que há de realmente novo no rural brasileiro". Cadernos da ciência e tecnologia, Brasília, V.19, nº ; p.37-67, 2002.

HAESBAERT, R. O Mito da Desterritorialização. Rio de Janeiro: Bertrand, 2004.

HAESBAERT, R. Da desterritorialização à multiterritorialidade. In: Encontro de Geógrafos 
da América Latina, X, 2005, São Paulo. Anais ... São Paulo: USP/EGAL, 2005.

IANNI, Otávio. O mundo agrário. In: A era do globalismo. Civilização Brasileira. Rio de Janeiro. 1996.

KAYSER, B. La renaissance rurale. Paris: Armand Colin, 1989.

LEFEBVRE, Henri. O direito à cidade. Tradução de Rubens Eduardo Frias. São Paulo: Moraes, 1991.

LOCATEL, Celso. Agricultura e ruralidade: uma abordagem. Modernização da agricultura, políticas públicas e ruralidade: mudanças e permanências na dinâmica rural das microrregiões de Jales e de Fernandópolis. 2004. Tese de Doutorado - UNESP - Presidente Prudente, São Paulo, 2004.

MACAÉ (RJ). Prefeitura. 2016. Disponível em: http://www.macae.rj.gov.br. Acesso em: fev. 2016.

MOREIRA, Roberto José. Cultura, política e o mundo rural na contemporaneidade. Estudos, Sociedade e Agricultura. Rio de Janeiro: CPDA UFRRJ, n² 20, p.113 - 143, abr. 2003.

MOREIRA, Roberto José. Ruralidades e globalizações: ensaiando uma interpretação. Rio de Janeiro, UFRRJ/CPDA, 2a ed. N.1, 2002.
RUA, J. Urbanidades e Novas Ruralidades no Estado do Rio de Janeiro: Algumas considerações teóricas. In: MARAFON, G.; RIBEIRO, M. Estudos de Geografia Fluminense. Rio de Janeiro: Infobook, 2002. p. 27-42.

RUA, João . Urbanidades no rural em um trecho da região serrana fluminense - a rodovia Teresópolis - Nova Friburgo. In: I Encontro de Grupos de Pesquisa - Agricultura, desenvolvimento regional e transformações sócio-espaciais, 2005, Rio de Janeiro. I Encontro de Grupos de Pesquisa, 2005.

RUA, J. Urbanidade no Rural: o devir de novas territorialidades. Campo - Território: Revista de Geografia Agrária. Uberlândia, V. I, p.82 - 106; Fev. 2006. Disponível em: < www.campoterritorio.ig.ufu.br $>$ acesso em: 22 de maio de 2014.

SANTOS, Milton. A Natureza do Espaço: espaço e tempo, razão e emoção. $3^{a}$ ed. São Paulo: Hucitec, 1999. 384 p.

SCHNEIDER, Sergio. A Pluriatividade na Agricultura Familiar. Porto Alegre: UFRGS, 2003.

VALLE, Teresa Losada. Mandioca de mesa, macaxeira ou aipim: a hortaliça negligenciada pelo Brasil. In: $47^{\circ}$ Congresso Brasileiro de Olericultura, Porto Seguro-BA; 2007, p. 1 - 11. Disponível em: < www.abhorticultura.com.br> acesso em: Abril de 2014.

VEIGA, José Eli da. A dimensão rural do Brasil. Estudos, Sociedade e Agricultura, Rio de Janeiro: CPDA-UFRRJ, n. 12, p. 71-94, abr., 2004. 